\title{
Cellulose carbamate derived cellulose thin films: preparation, characterization and blending with cellulose xanthate
}

\author{
Michael WeißI • Mathias Andreas Hobisch • Leena Sisko Johansson • \\ Kay Hettrich • Eero Kontturi • Bert Volkert • Stefan Spirk (D)
}

Received: 28 March 2019/Accepted: 26 June 2019/Published online: 4 July 2019

(C) The Author(s) 2019

\begin{abstract}
Cellulose carbamate (CC) was employed as a water-soluble precursor in the manufacturing of cellulose based thin films using the spin coating technique. An intriguing observation was that during spin coating of $\mathrm{CC}$ from alkaline aqueous solutions, regeneration to cellulose was accomplished without the addition of any further chemicals. After rinsing, homogeneous thin films with tunable layer thickness in a range between 20 and $80 \mathrm{~nm}$ were obtained. Further, CC was blended with cellulose xanthate in different ratios $(3: 1,1: 1,1: 3)$ and after regeneration the properties of the resulting all-cellulose blend thin films were investigated. We could observe some slight indications of phase separation by means of atomic force microscopy. The layer thickness of the blend
\end{abstract}

Electronic supplementary material The online version of this article (https://doi.org/10.1007/s10570-019-02600-z) contains supplementary material, which is available to authorized users.

M. Weiß1 · M. A. Hobisch · S. Spirk $(\bowtie)$

Institute for Paper, Pulp and Fibre Technology, Graz

University of Technology, Inffeldgasse 23, $8010 \mathrm{Graz}$,

Austria

e-mail: stefan.spirk@tugraz.at

L. S. Johansson · E. Kontturi

Department of Bioproducts and Biosystems (BIO2), Aalto

University, P.O.Box 16300, 00076 Aalto, Finland

K. Hettrich · B. Volkert

Fraunhofer Institute for Applied Polymer Research IAP, Geiselbergstrasse 69, 14167 Potsdam-Golm, Germany thin films was nearly independent of the ratio of the components, with values between 50 and $60 \mathrm{~nm}$ for the chosen conditions. The water uptake capability (80-90\% relative to the film mass) determined by $\mathrm{H}_{2} \mathrm{O} / \mathrm{D}_{2} \mathrm{O}$ exchange in a quartz crystal microbalance was independent of the blend ratio.

Keywords Cellulose carbamate $\cdot$ Cellulose xanthate $\cdot$ All cellulose blend films $\cdot$ Cellulose thin film $\cdot$ Cellulose swelling

\section{Introduction}

Despite being rather old, the Viscose process still is the most important and frequently used technology for the production of regenerated wood based fibers with annual production volumes exceeding 3.5 million tons, mainly for the textile industry (Wang et al. 2016; Hämmerle 2011). However, there are several environmental drawbacks of this technology. For instance, the necessity to use $\mathrm{CS}_{2}$ to form the cellulose precursor material (cellulose xanthate, CX), as well as the development of volatile sulfur containing compounds (e.g. $\mathrm{H}_{2} \mathrm{~S}, \mathrm{COS}$ ) during the regeneration procedure requires complex recovery technologies, which manifest into higher prices of the final fiber products. These disadvantages have led to the development of new fiber spinning technologies such as the Lyocell 
and the Ioncell processes that both avoid the use of cellulose derivatives by direct dissolution into NMMO/water and ionic liquids (Rosenau et al. 2001; Sixta et al. 2015). However, costs are still higher for fibers derived from these processes since also here the recovery of the solvents requires substantial energy input. Another technology that has raised attention in recent years is the Carbacell process. The Carbacell process relies on cellulose carbamate (CC), which is easily obtained by reacting cellulose with urea. CC is soluble in cold alkali and can be subjected to wet spinning processes similar to those in viscose plants (Fink et al. 2014). As regeneration bath, a diluted acid or a sodium carbonate solution can be used (Wendler et al. 2012). The similarities in the solvent, the spinning process and the regeneration bath also allows for fiber spinning of solutions containing $\mathrm{CX}$ and $\mathrm{CC}$, with the goal to reduce the usage of $\mathrm{CS}_{2}$ in the fiber manufacturing process.

In recent literature, the processing of regenerate cellulose fibers from spinning dopes, blended with CC and CX was described and mechanical properties of the obtained fibers were studied. But fundamental questions concerning the miscibility of the two cellulose derivatives or possibly occurring phase separation during various process steps, could not be answered in these macroscopic studies. In addition, development of dense core shell structured fibers during wet spinning and subsequent fiber stretching prohibits a detailed study of the cellulose interfaces in those blend materials (Protz et al. 2018).

Thus, the processing of cellulose thin films based on CC, CX and blends of these solutions delivers opportunities to study the influence of the $\mathrm{CC}$ on the properties of $\mathrm{CX}$ based materials. Cellulose thin films provide a confined two-dimensional network with a well-defined surface morphology and chemistry (Kontturi et al. 2006). Literature gives many examples, where thin films have been employed to study the influence of certain conditions on the behavior of cellulose and its derivatives, or to observe the interaction of cellulose with biopolymers or proteins (Ehmann et al. 2015; Mohan et al. 2017; Niegelhell et al. 2016; Niinivaara et al. 2016). In a previous work, some of us published a method for the processing of cellulose thin films based on the spin coating and following $\mathrm{HCl}$ vapor exposure of CX films (Weißl et al. 2018). This made us interested in the fundamental suitability of $\mathrm{CC}$ solutions to form thin film structures. As the processing of the $\mathrm{CC}$ can be assigned as green and sustainable, the solubility in diluted sodium hydroxide allows to avoid organic solvents and the regeneration in acidic media should also be possible in an acidic vapor phase. Further, CX and $\mathrm{CC}$ are soluble in the same solvent, offering opportunities to blend the solutions and spin coat cellulose thin films from two different sources, thereby creating all-cellulose blend thin films (Protz et al. 2018). The blending of these two promising and well known cellulose derivatives does not only allow to study cellulose-cellulose interfaces in a well-defined environment, but can be used to explore the influence of $\mathrm{CC}$ on $\mathrm{CX}$ during the formation and regeneration to cellulose. Through the confined two-dimensional structure, this blend film processing could show interactions and effects which are not visible in the wet spinning of blended solutions from $\mathrm{CC}$ and $\mathrm{CX}$.

\section{Experimental}

\section{Materials}

Cellulose carbamate (CC) with a DS of 0.3 ( $\mathrm{N}$ content $2.51 \%$ according to elemental analysis), a DP of 450 and a dry mass of $92 \%$ was provided from Fraunhofer Institute for Applied Polymer Research (PotsdamGolm, Germany) and used without any further treatment. Cellulose xanthate $(\mathrm{CX})$ stock solution with a cellulose content of $10 \mathrm{wt} \%$, a DS of 0.5 and a DP of 550 was provided from Lenzing AG (Lenzing, Austria). Sodium hydroxide, hydrochloric acid (37\%), sulfuric acid (95\%) and hydrogen peroxide (30\%) were purchased from VWR chemicals. De-ionized (DI) water was produced in house with an Elga PURELAB Prima (Bucks, United Kingdom) water treatment system. Chromafil Filters Xtra PVDF-45/25 $0.45 \mu \mathrm{m}$ were used as obtained. Single side polished silicon wafers from Siegert Wafers (Aachen, Germany, wafer thickness: $675 \pm 25 \mu \mathrm{m}, 1 \mathrm{~cm} \times 2 \mathrm{~cm}$ ) and gold coated glass slides from BioNavis (Tampere, Finland, gold layer thickness: $50 \mathrm{~nm}, 1 \mathrm{~cm} \times 2 \mathrm{~cm}$ ) were used as substrates for the cellulose thin films. QCMD sensors (QSX301) were purchased from nanoscience Instruments (phoenix, USA). For spin coating, a Polos 150. 
Cellulose carbamate film processing

For the spin coating process, CC $(1.0,1.5,2.0,2.5$ wt $\%$ ) was dissolved in $8 \% \mathrm{NaOH}$ solution at $-10{ }^{\circ} \mathrm{C}$ under vigorous stirring for $24 \mathrm{~h}$. The solutions were filtered through a $0.45 \mu \mathrm{m}$ filter and $80 \mu \mathrm{cm}^{-2}$ were transferred on the employed substrates. The slides used as substrates for the films were cleaned by dipping them into piranha acid $\left(\mathrm{H}_{2} \mathrm{SO}_{4}: \mathrm{H}_{2} \mathrm{O}_{2}=3: 1\right.$ (v/ v)) for $30 \mathrm{~min}$ (10 min for gold slides) followed by intense rinsing with MilliQ water in advance. The spin coating itself was performed on a Polos Spin 150i (from SPS Europe, Ingolstadt, Germany) with a speed of $4000 \mathrm{rpm}$ and an acceleration of $2500 \mathrm{rpm} / \mathrm{s}$ for $60 \mathrm{~s}$ as already described in previous work (Weiß1 et al. 2018, 2019). After spin coating, the films were stored for at least $1 \mathrm{~h}$ under ambient conditions before they were rinsed with $10 \mathrm{ml}$ water and dried under nitrogen flow. Afterwards, the films were treated in acid vapor atmosphere $(37 \% \mathrm{HCl})$ for a period of $20 \mathrm{~min}$ (Figure S1, SI) with subsequent rinsing (10 ml water) and a final drying process at $105^{\circ} \mathrm{C}$ for $60 \mathrm{~min}$.

\section{$\mathrm{CC} / \mathrm{CX}$ blend film processing}

A $2.0 \mathrm{wt} \% \mathrm{CX}$ solution was prepared by diluting the provided stock solution with $8 \% \mathrm{NaOH}$ under rigorous shaking by hand for a period of $2 \mathrm{~min}$ and subsequent filtration through a $0.45 \mu \mathrm{m}$ filter. This CX solution was mixed with a $2.0 \mathrm{wt} \% \mathrm{CC}$ solution in different ratios $(1: 0,3: 1,1: 1,1: 3,0: 1)$ for a period of $10 \mathrm{~min}$ under sonication. This solution was deposited on a substrate and subjected to spin coating ( $\mathrm{v}=4000 \mathrm{rpm}$, $\mathrm{a}=2500 \mathrm{rpm} / \mathrm{s}, \mathrm{t}=60 \mathrm{~s}$ ), followed by $\mathrm{HCl}$ vapor exposure $(20 \mathrm{~min})$ with subsequent rinsing $(10 \mathrm{ml}$ water) and drying in a stream of nitrogen.

\section{Optical microscopy}

Light microscopy images were taken by an Olympus BX60 equipped with an Olympus E-520 camera. Prior to investigating the samples, carrier substrates were fixed on a glass layer.

\section{Elemental analysis}

Elemental analysis was carried out by a vario MICRO analyser from Elementar (Langensebold, Germany), where the samples are burned within a jet injection of oxygen. The gaseous components were purified and separated on a TPD column, before quantification with a thermal conductivity detector. Helium was used as a carrier gas.

X-ray photoelectron spectroscopy (XPS)

Surface chemistry was evaluated with XPS, using a Kratos AXIS Ultra photoelectron sprctrometer with monochromated $\mathrm{Al} \mathrm{K} \alpha$ irradiation at low power $(100 \mathrm{~W})$ and under neutralization. Prior to the experiment samples were pre-evacuated overnight, in order to stabilize experimental conditions. Samples were measured together with the lab-defined of in situ reference of $100 \%$ cellulose (Whatman). Both wide energy resolution scans, with $1 \mathrm{eV}$ step and $80 \mathrm{eV}$ $\mathrm{CAE}$, and high resolution scans of $\mathrm{C} 1 \mathrm{~s}$ and $\mathrm{O} 1 \mathrm{~s}$ regions with $0.1 \mathrm{eV}$ step and $20 \mathrm{eV} \mathrm{CAE}$ were recorded on 2-3 locations. Nominal analysis spot size is $400 \times 800 \mu \mathrm{m}$. All binding energies were chargecorrected using the cellulose $\mathrm{C} 1 \mathrm{~s}$ main component of $\mathrm{C}-\mathrm{O}$ at $286.7 \mathrm{eV}$, after fitting the high resolution carbon data into four Gaussian components with equal half widths, using CasaXPS software (Johansson and Campbell 2004).

\section{Profilometry}

The layer thickness was determined with a Bruker DekTak XT surface profiler. The scan length was set to $1000 \mu \mathrm{m}$ over the duration of $3 \mathrm{~s}$ with the hills and valleys scanning profile. The diamond stylus had a radius of $12.5 \mu \mathrm{m}$ and the employed force was $3 \mathrm{mg}$. The sample was samples were scraped before measuring and the obtained profile was then used to determine the thickness. Each layer thickness has been determined by averaging 9 measurements on three different slides.

\section{Attenuated total reflection infrared spectroscopy}

The infrared spectra were recorded with an ALPHA FT-IR spectrometer (Bruker; Billerica, MA, U.S.A.). For the measurement, an attenuated total reflection (ATR) attachment was used with 48 scans at a resolution of $4 \mathrm{~cm}^{-1}$ and a scan range between 4000 and $400 \mathrm{~cm}^{-1}$. The samples were prepared on $\mathrm{Au}-$ coated glass slides (SPR102-AU). The data were analyzed with OPUS 6.0 software. 
Atomic force microscopy

The surface was investigated with a Tosca ${ }^{\mathrm{TM}}$ 400 atomic force microscope (AFM, Anton Paar, Austria) in tapping mode using Al-coated cantilevers (ARROW-NCR, NanoWorld AG, Switzerland) with a resonance frequency of $285 \mathrm{kHz}$ and a force constant of $42 \mathrm{~N} \mathrm{~m}^{-1}$. All measurements were acquired at room temperature under ambient conditions. All calculations and image processing was performed with Tosca ${ }^{\mathrm{TM}}$ analysis (V7.4.8341, Anton Paar, Austria).

Contact angle and surface free energy determination

For the calculation of the surface free energy (SFE) Milli-Q water $\left(\geq 18 \mathrm{M} \Omega \mathrm{cm}^{-1}\right)$ and diiodomethane were employed as test liquids. The drop shape analysis was done in the sessile drop modus at $25^{\circ} \mathrm{C}$ with a DSA100 system (Krüss GmbH, Hamburg, Germany) equipped with a T1E CCD video camera ( $25 \mathrm{fps})$. The dispense rate of the three $\mu \mathrm{L}$ droplets was adjusted to $256 \mu \mathrm{L} / \mathrm{min}$ and the time before the image was captured was set to $1 \mathrm{~s}$. Each sample was measured at least six times on at least two samples. The contact angle (CA) calculations (software: DSA1 v 1.90) were performed with Young-Laplace equation and the surface free energy calculation according to the Owens-Wendt-Rabel \& Kaelble method (Owens and Wendt 1969).

Quartz crystal microbalance with dissipation monitoring

A QCM-D from Q-Sense (Gothenburg, Sweden) with simultaneous detection of the resonance frequency $(\Delta f)$ and energy dissipation $(\Delta D)$ of an oscillating piezoelectric crystal was employed. Dissipation describes the frictional losses which cause a damping of the oscillation in correlation to the viscoelastic properties to the materials absorbed on the crystals. Rigid layers are assumed to fully couple to the oscillation of the crystal, where the change in frequency $\Delta \mathrm{f}$ is given by the Sauerbrey equation

$\Delta m=C \frac{\Delta f_{n}}{n}$
$C$ is the Sauerbrey constant $\left(-17.7 \mathrm{ng} \mathrm{Hz}^{-1} \mathrm{~cm}^{-2}\right.$ for a $5 \mathrm{MHz}$ crystal), $\Delta m$ is the changing mass of the crystal due to the adsorbed layer and $n$ is the overtone number (Sauerbrey 1959). The baseline resonance frequencies for the crystals were determined before depositing the cellulose layers and subsequent determination of the water content in the layers was done with a $\mathrm{H}_{2} \mathrm{O} / \mathrm{D}_{2} \mathrm{O}$ exchange experiment, as described by Kittle et al. (2011) and Mohan et al. (2012).

\section{Determination of the water equilibrium content}

By exploiting differences in viscosity and density of $\mathrm{H}_{2} \mathrm{O} / \mathrm{D}_{2} \mathrm{O}$, the amount of water uptake by the accessible parts of the thin films can be determined. Based on the Kanazawa (Keiji and Gordon 1985) equation it follows:

$\frac{\Delta f_{\mathrm{H}_{2} \mathrm{O}}}{n}=\frac{\frac{\Delta f_{\text {film }}}{n}-\frac{\Delta f_{\text {bare }}}{n}}{\frac{\rho_{\mathrm{D}_{2} \mathrm{O}}}{\rho_{\mathrm{H}_{2} \mathrm{O}}}-1}$

where $\Delta f($ film $)$ and $\Delta f($ bare $)$ describe the frequency shifts caused by an exchange of $\mathrm{H}_{2} \mathrm{O}$ by $\mathrm{D}_{2} \mathrm{O}$ on a bare substrate and on substrates coated with a blend film respectively. The density $\rho$ is $0.9982 \mathrm{~g} / \mathrm{cm}^{3}$ for $\mathrm{H}_{2} \mathrm{O}$ and $1.1050 \mathrm{~g} / \mathrm{cm}^{3}$ for $\mathrm{D}_{2} \mathrm{O}, n$ is the overtone number and $\Delta f\left(\mathrm{H}_{2} \mathrm{O}\right)$ is the frequency shift, induced by the water absorbed in the cellulose films. With the Sauerbrey equation, $\Delta f\left(\mathrm{H}_{2} \mathrm{O}\right)$ can directly be transferred in a total water content.

$\Gamma_{\text {water }}=C * \frac{\Delta f_{\mathrm{H}_{2} \mathrm{O}}}{n}$

After recording the resonance frequencies before and after coating, the films were equilibrated with MilliQ water (flow rate: $0.1 \mathrm{ml} / \mathrm{min}$ ) for a period of $30 \mathrm{~min}$. Afterwards, the water was exchanged by $\mathrm{D}_{2} \mathrm{O}$ and the cells were flushed with $\mathrm{D}_{2} \mathrm{O}$ until no further change in frequency was observed (i.e. for $15 \mathrm{~min}$ ). The last step was to change back to water again until equilibration was reached $(15 \mathrm{~min})$. The resulting frequency shifts before and after injection of $\mathrm{D}_{2} \mathrm{O}$ were used to determine $\Gamma_{\text {water }}$ according to (3). The $\mathrm{H}_{2} \mathrm{O} / \mathrm{D}_{2} \mathrm{O}$ exchange was also done with uncoated crystals that served as reference. For each experiment, at least three parallel measurements have been performed. The determined mass of the exchanged 
water was then correlated to the film mass to normalize the results to the thickness of the films.

\section{Results and discussion}

Formation and characterization of pure $\mathrm{CC}$ thin films

The spin coating of CC solutions with concentrations between 1.0 and $2.5 \mathrm{wt} \%$ yielded films with full and regular coverage of the substrates as determined by optical microscopy. Below a concentration of 1.0 $\mathrm{wt} \%$, the coverage of the slide was incomplete and inhomogeneous; above $2.5 \mathrm{wt} \%$ the solution could not be filtered anymore and the resulting films showed a high surface roughness and irregularities caused by aggregates (data not shown).

After spin coating was finished, needle-shaped salt crystals formed a top layer and covered the whole substrate within seconds (Figure S2, SI). After rinsing the films with de-ionized water, the crystalline top layer was washed away and a smooth cellulose layer with a defined morphology remained on the substrate. The following acid vapor deposition as well as the drying process did not cause a visible change in the surface morphology of the films. The layer thickness for films prepared from different $\mathrm{CC}$ solutions is depicted in Fig. 1a. It is noticeable that the evolution of the layer thickness during the processing is similar for the different concentrations. Prior to rinsing the films with water, a thickness of 200 to $400 \mathrm{~nm}$ was determined. After rinsing and simultaneous removal of the salt crystallites with water, the thickness decreased significantly to $22,42,56$ and $75 \mathrm{~nm}$ for concentrations of 1.0, 1.5, 2.0 and $2.5 \mathrm{wt} \%$, respectively. Subsequent $\mathrm{HCl}$ vapor treatment or the drying step at $105{ }^{\circ} \mathrm{C}$ did not show strong impact on the film thickness.

Figure $1 \mathrm{~b}$ summarizes the IR spectra of the thin films during processing and the corresponding reference materials. The $\mathrm{CC}$ used as starting material features characteristic broad bands in a region of $3600-3100 \mathrm{~cm}^{-1}$ (OH vibration) and around $2900 \mathrm{~cm}^{-1}$ (CH stretching) followed by a series of small bands between 1430 to $1150 \mathrm{~cm}^{-1}(\mathrm{C}-\mathrm{O}-\mathrm{H}$ bending at $1430 \mathrm{~cm}^{-1}, \mathrm{C}-\mathrm{H}$ deformation at $1372 \mathrm{~cm}^{-1}, \mathrm{OH}$ in plane deformation at 1330 and at $1200 \mathrm{~cm}^{-1}$ ) and strong overlapping bands between 1160 and $890 \mathrm{~cm}^{-1}$ (asym. C-O-C vibration at $1155 \mathrm{~cm}^{-1}$, sym. C-O vibration at $1060 \mathrm{~cm}^{-1}, \mathrm{C}-\mathrm{O}$ stretching at $1035 \mathrm{~cm}^{-1}$ and $\mathrm{C}-\mathrm{O}-\mathrm{C}$ valence vibration at $899 \mathrm{~cm}^{-1}$ ) (Široký et al. 2010). In addition to the cellulose induced bands, two significant bands at 1620 and $1700 \mathrm{~cm}^{-1}$ indicate the presence of carbamates (Nada et al. 2000; Xiong et al. 2017).

After spin coating, the spectrum of the precipitated CC showed particular differences in comparison to the CC source material. Strong overlapping bands at 1480 , 1420 and $880 \mathrm{~cm}^{-1}$ are characteristic for sodium carbonate and clearly dominate the spectrum, whereas bands caused by cellulose and sodium hydroxide are
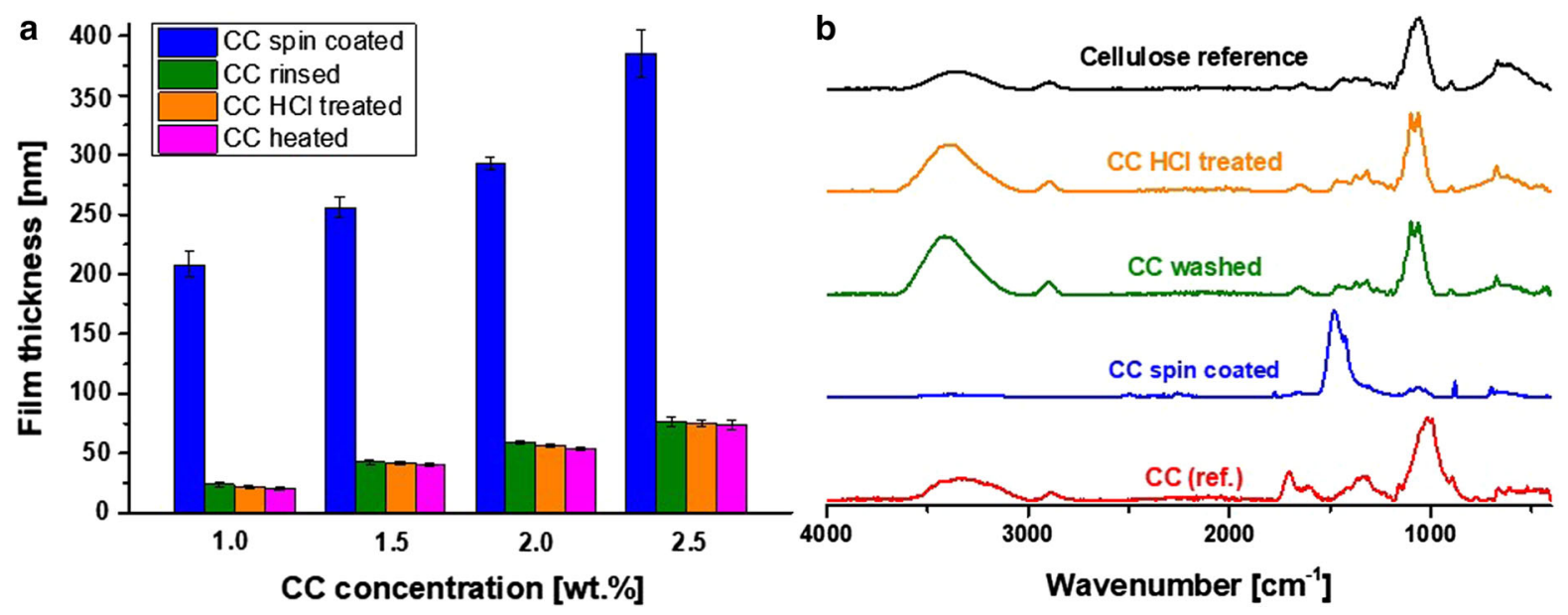

Fig. 1 a ATR-IR spectra of the CC source (ref.) and the CC during the processing to cellulose thin films. b Film thickness of CC thin films during processing of different $\mathrm{CC}$ concentrations 


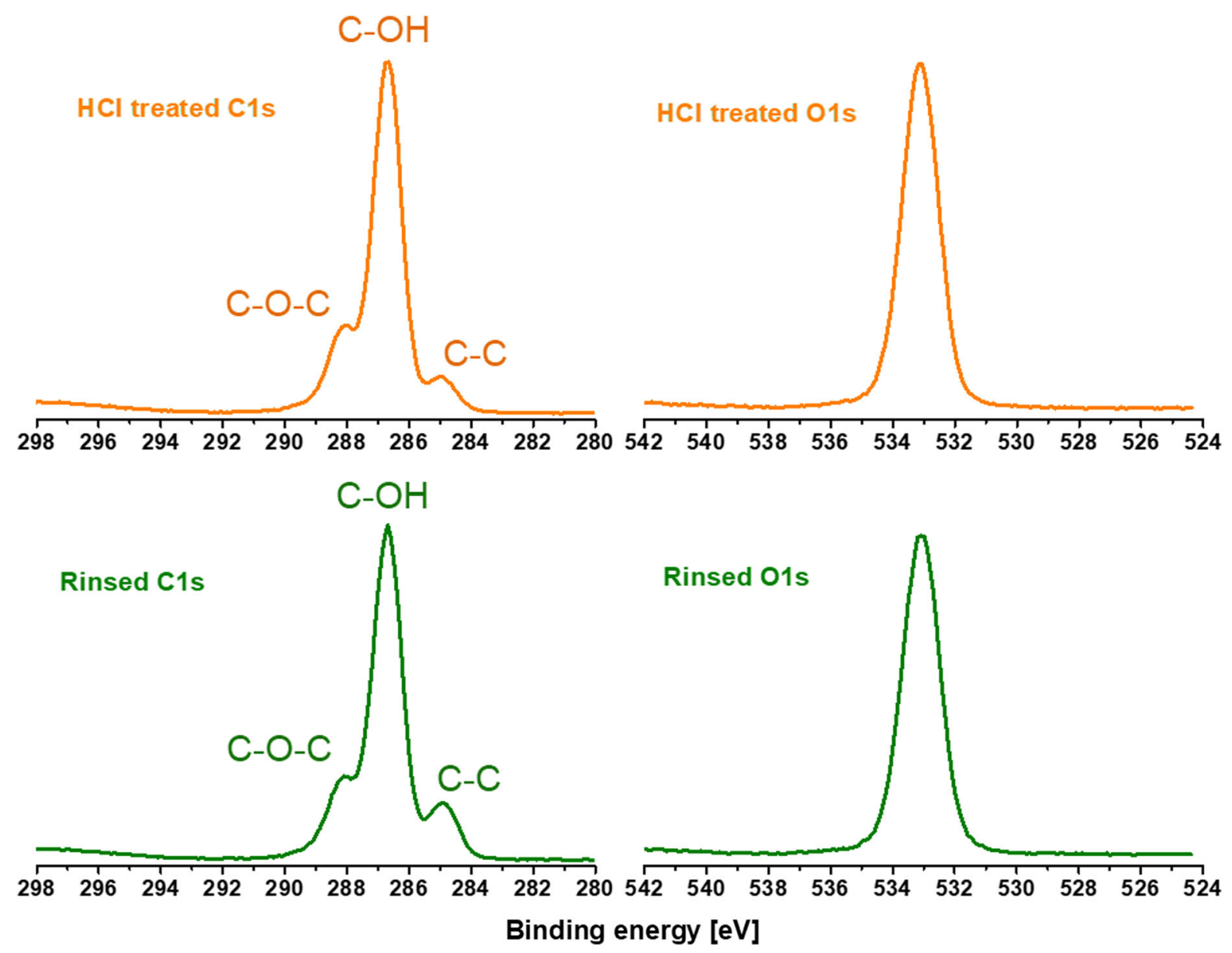

Fig. 2 XPS high-resolution spectra of $\mathrm{C}$ and $\mathrm{O}$ environment after rinsing and $\mathrm{HCl}$ vapor treatment

much less pronounced (Neufeld et al. 2002). The intensive sodium carbonate band and the described growth of a crystalline structures after spin coating suggest the expected formation of a sodium carbonate top layer (Weißl et al. 2018). After rinsing the substrates, a spectrum matching all the cellulose bands as described by Siroky et al. was obtained (Široký et al. 2010). Further treatment in an $\mathrm{HCl}$ vapor phase or drying at $105{ }^{\circ} \mathrm{C}$ did not affect the cellulose structure according to data from infrared spectroscopy. The detailed spectra are shown in Figure S3 to S6, SI. The feature at 1647 to $1650 \mathrm{~cm}^{-1}$ can be assigned to adsorbed water on cellulose as described in literature. This band is present in all the spectra even in those that do not contain any cellulose carbamate (i.e. cellulose from CX).

To further confirm that regeneration of the $\mathrm{CC}$ already occurs during spin coating, XPS was employed. The XPS survey spectra did not reveal the presence of nitrogen and sodium in the films after rinsing (Figure S7, SI). Figure 2 summarizes carbon and oxygen high resolution spectra of spin coated CC after rinsing the films with water and after additional $\mathrm{HCl}$ vapor treatment.

Both, the $\mathrm{C} 1 \mathrm{~s}$ and the $\mathrm{O} 1 \mathrm{~s}$ environments match the bonding energies previously described for cellulose materials. The $\mathrm{C} 1 \mathrm{~s}$ peaks showed three single environments namely $\mathrm{C}-\mathrm{C}(\mathrm{H})$ at $284.5, \mathrm{C}-\mathrm{OH}$ at 286.5 and $\mathrm{C}-\mathrm{O}-\mathrm{C}$ at $288 \mathrm{eV}$, respectively, whereas the $\mathrm{O} 1 \mathrm{~s}$ peak features only one environment at $533.5 \mathrm{eV}$. A shift in the described binding energies or new bands suggesting changes in the cellulose structure, could not be detected within all post spin coating treatments (Shchukarev et al. 2002).

The conversion to cellulose by spin coating is an intriguing observation. To the best of our knowledge, 

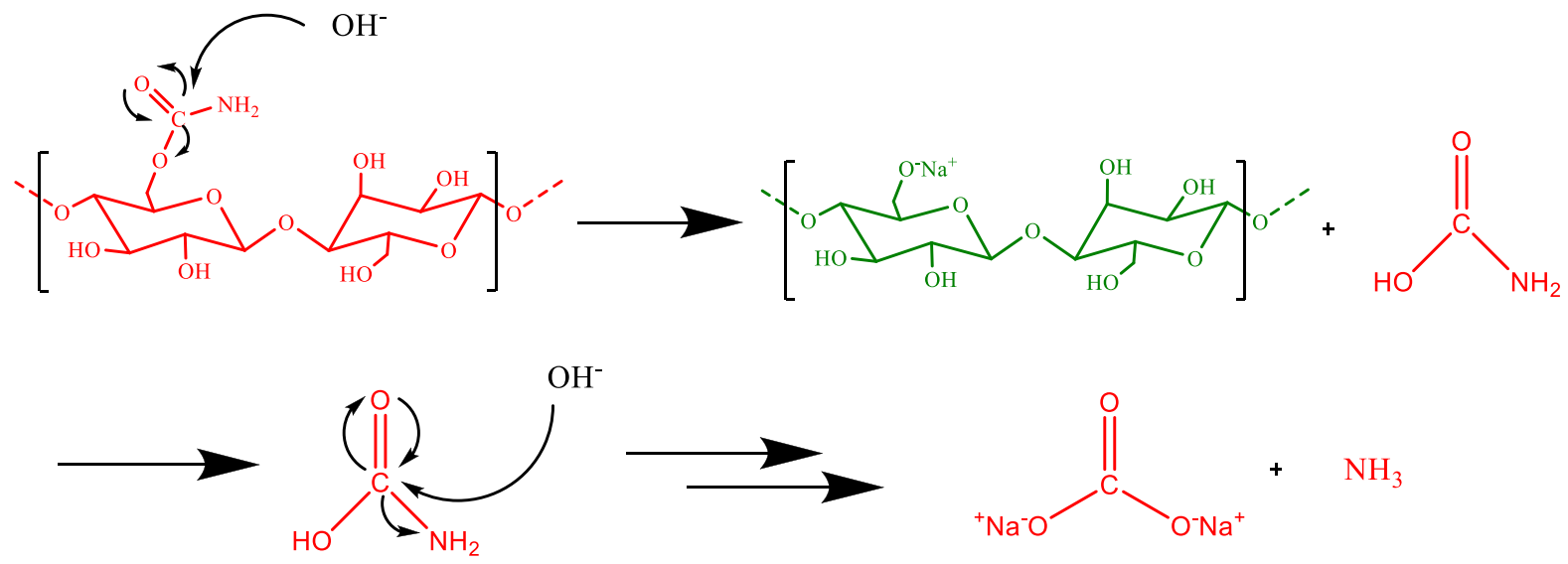

Scheme 1 Carbamate decomposition induced by the increasing basicity of the system during ongoing spin coating

there are not any reactions that are induced by spin coating in literature. During spin coating, the basicity of the system is steadily increasing due to water evaporation (i.e. higher hydroxide concentration). It is known that primary carbamates in general may be subject to decomposition under extreme alkaline conditions via an addition-elimination mechanism (Scheme 1). In such reactions, the nucleophile $(\mathrm{OH}-)$ attacks the carbon at the carbamate group under elimination of $\mathrm{NH}_{3}$ (Moidoveanu and David 2002). These reactions are very often kinetically driven, i.e. steric hindrance plays a role and determines under which conditions these reactions actually take place. In case of cellulose, the carbamate group is sterically protected and anchored on a polymer, thereby slowing down the reaction (Fu et al. 2014; Nada et al. 2000). There are reports to regenerate cellulose carbamate fibers in diluted hot alkaline solutions, corroborating the kinetic nature of the decomposition reaction (Klemm et al. 2005; Kunze and Fink 2005). During spin coating of $\mathrm{CC}$ solutions, the conversion to cellulose probably involves the diffusion of the labile carbamic acid to the cellulose-air interface, where it is decomposed to form sodium carbonate under elimination of ammonia. This would also explain the formation of the crystalline sodium carbonate layer shortly after spin coating has been accomplished and is supported by the ATR IR spectra that show all the typical bands associated with sodium carbonate.

AFM was employed to gain further information about the surface morphology and structure of the CC films. Compared to cellulose thin films from different sources like trimethylsilyl cellulose (TMSC)
(Niegelhell et al. 2016; Schaub et al. 1993) or cellulose xanthate (CX) (Weißl et al. 2018), the surface of CC thin films features more aggregates $(10-13 \mathrm{~nm})$ concomitant with slightly higher roughness. The AFM images (Fig. 3) suggest that concentrations as high as $1.0 \mathrm{wt} \%$ are suitable to completely cover the substrates. The morphology of films was regular and smooth with a RMS roughness between $5 \mathrm{~nm}$ (lowest concentration) and $12 \mathrm{~nm}$ (highest concentration). Compared to the increase in the root mean square (RMS) roughness with increasing CC concentration, no trend of increasing or decreasing surface roughness or any other change in surface morphology could be identified within the single processing steps (Figure S8, SI).

$\mathrm{CC}$ films spin coated from a $1.5 \mathrm{wt} \%$ solution displayed static water contact angles between $12^{\circ}$ and $27^{\circ}$, depending on the post treatment. At higher CC concentrations used for spin coating, the development of the contact angle followed the same direction but the range between the different treatments was much smaller (from $19^{\circ}$ to $26^{\circ}$ for $2.0 \mathrm{wt} \% \mathrm{CC}$, and from $29^{\circ}$ to $32^{\circ}$ for $2.5 \mathrm{wt} \%$ ).

The SFE of films spin coated from different concentrations was determined from the $\mathrm{H}_{2} \mathrm{O}$ and diiodomethane contact angles following the Owens, Wendt, Reynolds and Kaeble method (Owens and Wendt 1969). The obtained SFE (66-77 $\mathrm{mN} / \mathrm{m})$ are in the range reported for cellulose thin films (Fig. 4). The slight variations in the SFE values are caused by the changes in the surface roughness of the films since the chemistry of the films is the same. Such deviations in SFEs were also observed for cellulose thin films 

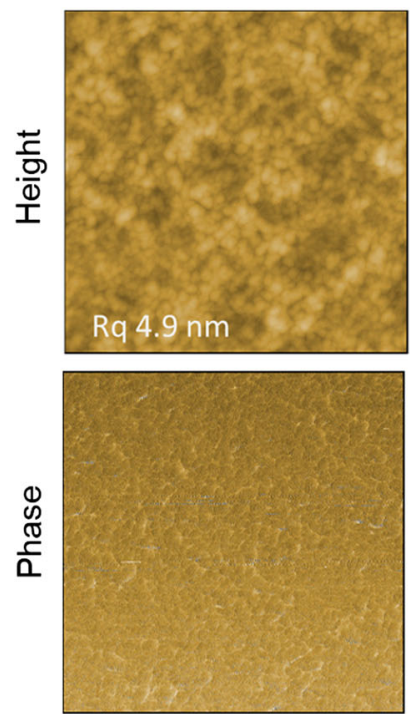

$1.0 \% \mathrm{CC}$
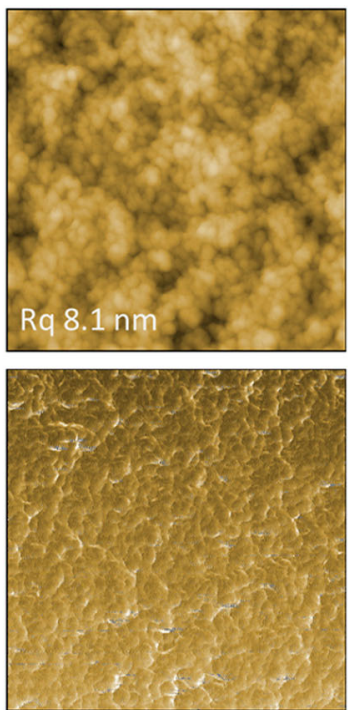

$1.5 \% \mathrm{CC}$
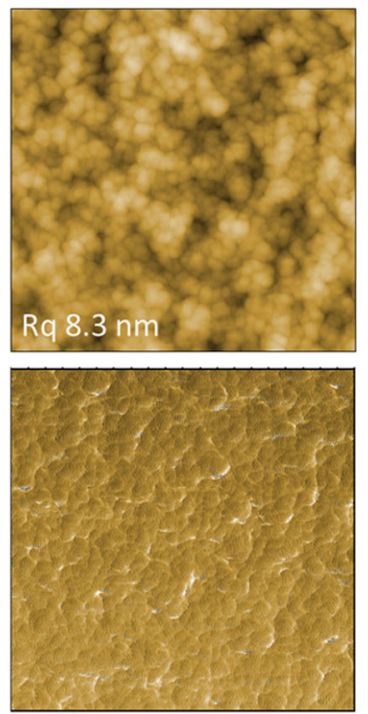

$2.0 \% \mathrm{CC}$
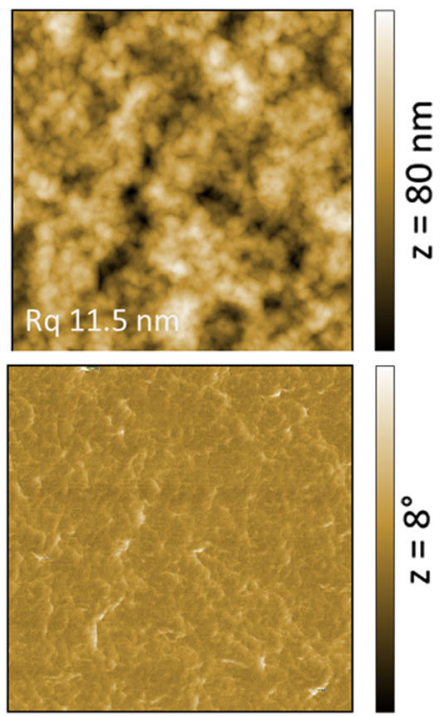

$2.5 \% \mathrm{CC}$

Fig. $32 \times 2 \mu \mathrm{m}^{2}$ AFM height (upper row) and phase (lower row) images of CC based thin films after spin coating and rinsing with water; starting with concentrations from 1.0 to $1.5,2.0$ and $2.5 \mathrm{wt} \%$

derived from other precursors (Mohan et al. 2011; Weiß1 et al. 2018, 2019).

Formation and characterization of CC/CX blend films

$\mathrm{CC}$ and $\mathrm{CX}$ are both soluble in $8 \% \mathrm{NaOH}$ solutions which was exploited to blend solutions in 1:3, 1:1 and 3:1 ratios (v/v). After spin coating the blend solutions, and subsequent regeneration to all-cellulose blend thin films, their properties were determined and correlated to cellulose thin films derived from $\mathrm{CX}$ and $\mathrm{CC}$, respectively. $\mathrm{CX}$ does not regenerate during spin coating as demonstrated in previous reports; therefore an $\mathrm{HCl}$ vapor treatment was performed to ensure conversion of the CX domains to cellulose (Weißl et al. 2018, 2019). The domains consisting of CC were not affected by this procedure as discussed above (Figs. 1, 2, 3).

Taking a closer look into the ATR-IR spectra of the blend films and reference materials (Fig. 5a), the region between 850 and $950 \mathrm{~cm}^{-1}$ attracts attention. For the pure $\mathrm{CX}$, the bands can be assigned to vibrations related to sodium sulfide $\left(1420,920 \mathrm{~cm}^{-1}\right)$ and sodium trithiocarbonate $(1670,1427,925$ and $885 \mathrm{~cm}^{-1}$ ). After $\mathrm{HCl}$ vapor exposure and rinsing with water, the blend films and the source materials were both fully regenerated and infrared spectroscopy only

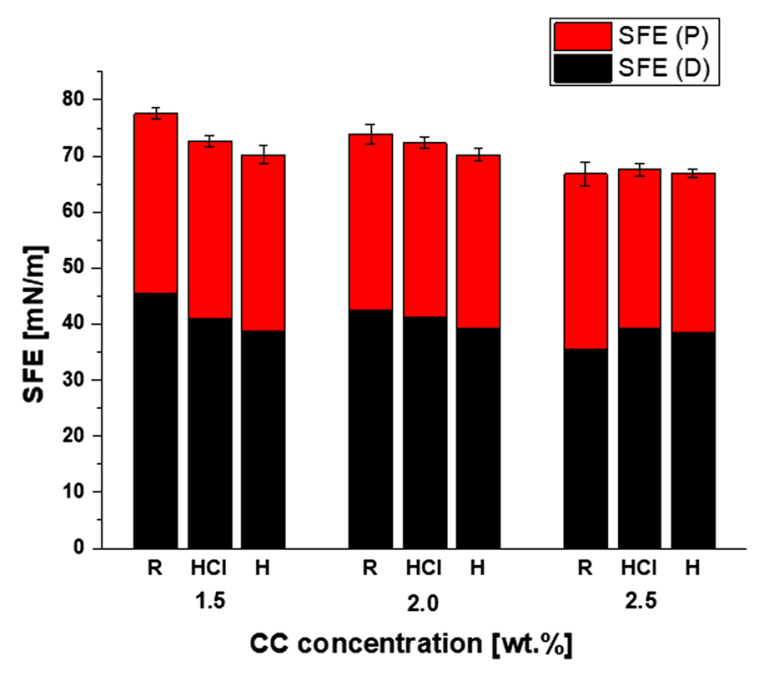

Fig. 4 SFE values calculated with the $\mathrm{H}_{2} \mathrm{O}$ and diiodomethane contact angles, whereby $\mathrm{D}$ describes the disperse contribution and $\mathrm{P}$ describes the polar contribution to the overall surface free energy ( $\mathrm{R}$, rinsed; $\mathrm{HCl}, \mathrm{HCl}$ treated and $\mathrm{H}$, heat treatment at $105^{\circ}$ for $1 \mathrm{~h}$ )

revealed bands related to cellulose (Figure S9, SI). The IR spectra in combination with XPS of the pure CC and the CX shown in a previous publication confirm the full regeneration of the different cellulose derivatives to yield all-cellulose blend films (Weißl et al. 2019). 
a

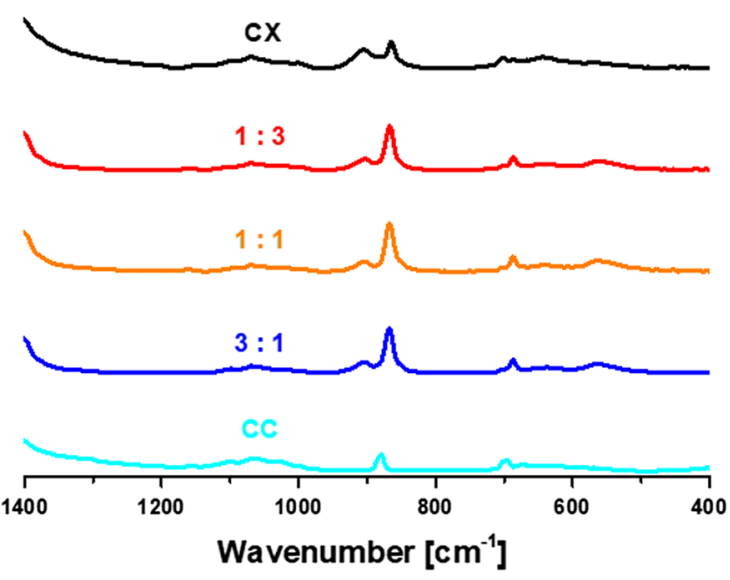

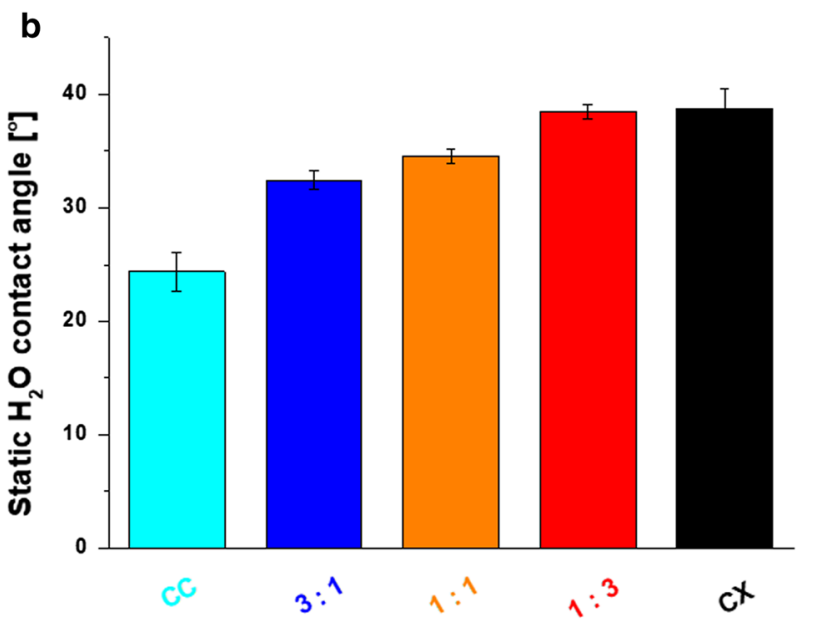

Fig. 5 a ATR-IR spectra of $2 \% \mathrm{CX}, 2 \% \mathrm{CC}$ and blends $(1: 3,1: 1,3: 1)$ after spin coating $\mathbf{b} \mathrm{H}_{2} \mathrm{O}$ contact angles of $2 \% \mathrm{CX}, 2 \% \mathrm{CC}$ and blend $(1: 3,1: 1,3: 1)$ films after $\mathrm{HCl}$ vapor treatment and rinsing with water

The determination of the layer thickness was executed by stylus profilometry. The reference materials had a thickness of 57 and $59 \mathrm{~nm}$ for $\mathrm{CC}$ and $\mathrm{CX}$, respectively. The thickness of the blend films were all in the range of $52 \mathrm{~nm}$ after regeneration and rinsing, regardless of the blend ratio (Figure S10, SI).

Determination of the static $\mathrm{H}_{2} \mathrm{O}$ contact angles is documented in Fig. 5b. The pure CC film had a contact angle of $24^{\circ}$ after $\mathrm{HCl}$ vapor exposure and with increasing CX content in the blend films, the contact angle was continuously increasing, until a value of $37^{\circ}$ — similar to the pure $\mathrm{CX}$ based film—was reached. The increase in the contact angle is unlikely caused by any chemical difference in the films but connected to a change in the surface morphology for the CC and the CX based layers. If the Wenzel equation is used for correcting the contact angles for the roughness of the films, differences between the films are rather small $\left(33^{\circ}-38^{\circ}\right.$ for water; Figure S11a, SI). The surface free energy followed the linear behavior, shown in the contact angle measurements, ranging from $72 \mathrm{mN} / \mathrm{m}$ for pure CC to $64 \mathrm{mN} / \mathrm{m}$ for pure $\mathrm{CX}$ based films (Figure S11b, SI).

AFM is employed to check the miscibility of CC and $\mathrm{CX}$ on a microscale. The evaluation of the surface morphology is summarized in Fig. 6 and indeed, slight
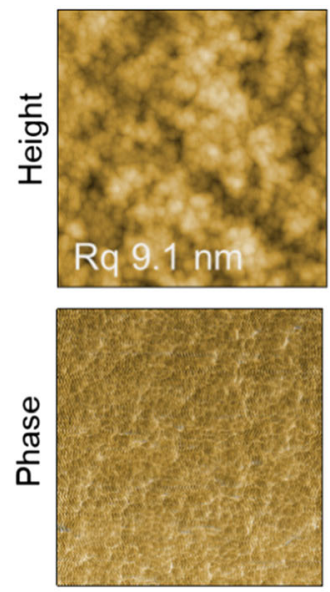

$\mathrm{CC}$
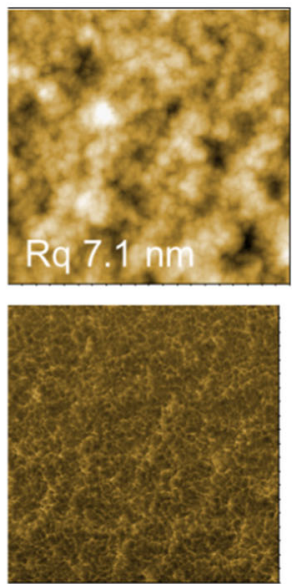

3:1
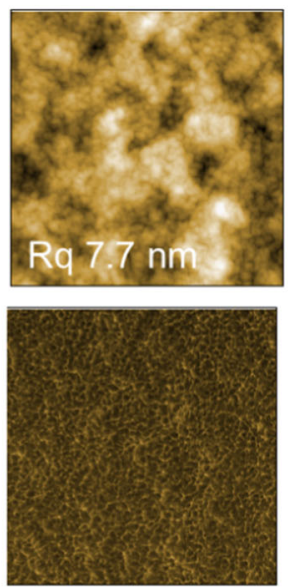

$1: 1$
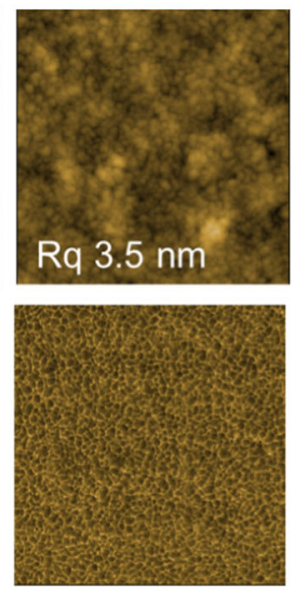

$1: 3$
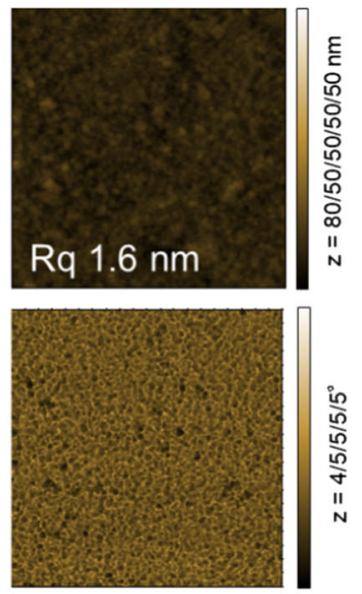

CX

Fig. $62 \times 2 \mu \mathrm{m}^{2}$ AFM height (upper raw) and phase (lower raw) images of $2 \% \mathrm{CC}$, blend $(3: 1,1: 1,1: 3)$ and $2 \% \mathrm{CX}$ films after $\mathrm{HCl}$ vapor treatment and rinsing with water 


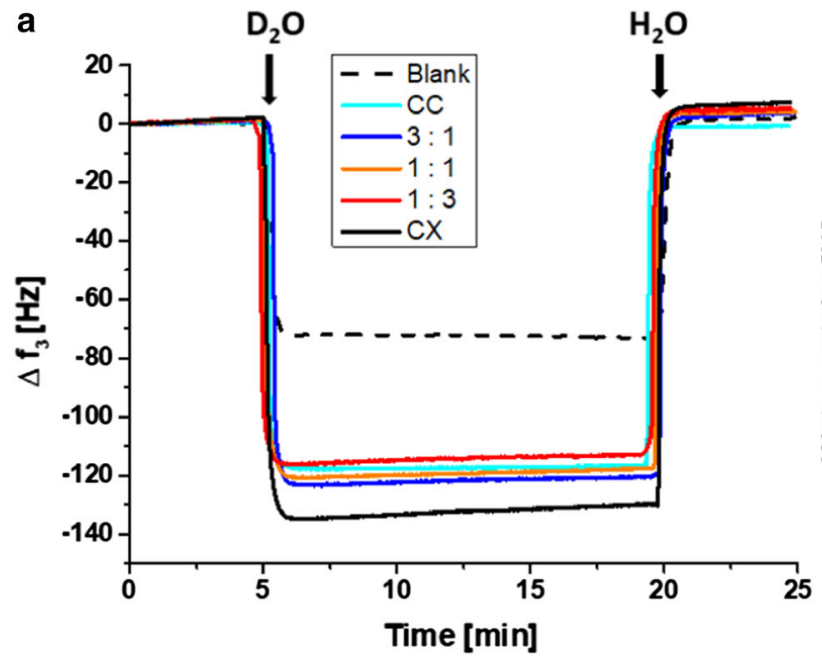

Fig. 7 a QCM-D monitored frequency shifts $\left(\Delta \mathrm{f}_{3}\right)$ of $2 \% \mathrm{CX}$, $2 \% \mathrm{CC}$ and blend $(1: 3,1: 1,3: 1)$ films in a $\mathrm{H}_{2} \mathrm{O} / \mathrm{D}_{2} \mathrm{O}$ exchange experiment. Flow rate: $0.1 \mathrm{ml} \mathrm{min}^{-1}$, equilibration time in $\mathrm{H}_{2} \mathrm{O}$

differences in surface structure and in the roughness were observable. The detailed mechanism on the formation of the structures visible in the phase images remained unclear.

The CC based films showed large bulky substructures, causing pronounced hills and valleys. These structures were further reflected in the RMS roughness of the thin films, where pure $\mathrm{CC}$ films had $\mathrm{R}_{\mathrm{q}}$ values of around $10 \mathrm{~nm}$. With increasing CX content in solution for preparing the blend films, the substructures became smaller and the surface showed a more regular shape. The RMS roughness decreased to $3.5 \mathrm{~nm}$ for the blend films prepared from the 1:3 CC:CX ratio. The cellulose film prepared from pure $\mathrm{CX}$ had the smallest RMS roughness among all investigated samples.

Finally, the water uptake and the swelling behavior of the blend films were investigated by a $\mathrm{H}_{2} \mathrm{O} / \mathrm{D}_{2} \mathrm{O}$ exchange monitored in a QCM-D device (Kittle et al. 2011; Mohan et al. 2012). In such exchange experiments, the different densities of $\mathrm{H}_{2} \mathrm{O}$ and $\mathrm{D}_{2} \mathrm{O}$ are exploited to determine $\Gamma_{\text {water }}$ according to Eqs. (2) and (3). Since thicker films incorporate more water than thinner ones, the results need to be normalized to the film thickness or mass if one aims at comparing water contents of films with varying thicknesses.

Figure $7 \mathrm{a}$ shows the frequency shifts of a bare substrate and the cellulose covered substrates during the $\mathrm{H}_{2} \mathrm{O} / \mathrm{D}_{2} \mathrm{O}$ exchange recorded by QCM-D. It can be clearly seen that the frequency after the $\mathrm{D}_{2} \mathrm{O}$ injection b

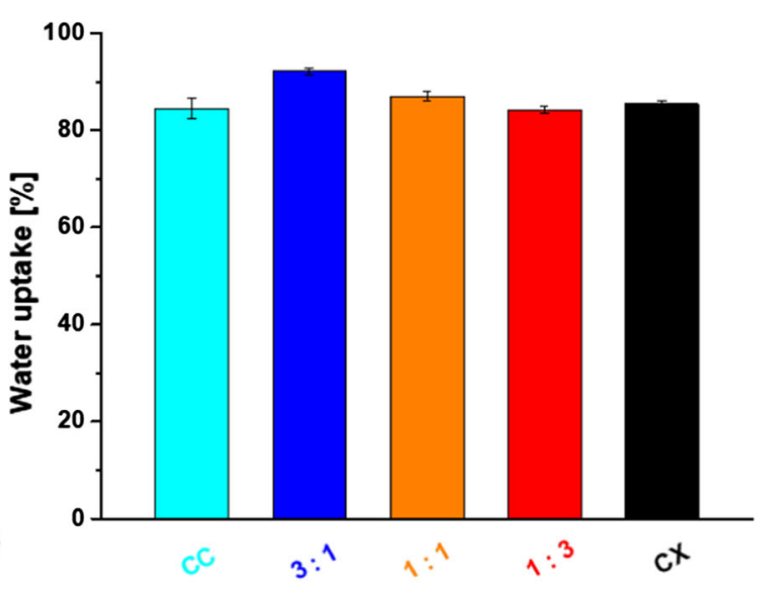

before D2O exchange: $30 \mathrm{~min}$ (only the last $5 \mathrm{~min}$ are shown for clarity) b Water uptake of the reference materials and the blend films during the $\mathrm{H}_{2} \mathrm{O} / \mathrm{D}_{2} \mathrm{O}$ exchange experiment

decreased and reached the initial frequency after exchanging back to $\mathrm{H}_{2} \mathrm{O}$, i.e. there is not any hysteresis.

The black dashed line represents the bare substrate and shows a $\Delta \mathrm{f}_{3}$ shift of ca. $-71 \mathrm{~Hz}$ between $\mathrm{H}_{2} \mathrm{O}$ and $\mathrm{D}_{2} \mathrm{O}$. If a cellulose layer was present on the substrates, the $\Delta \mathrm{f}_{3}$ were significantly higher and in the range of -115 up to $-120 \mathrm{~Hz}$, where the blend films $(1: 3,1: 1 ; 3: 1)$ and the pure $\mathrm{CC}$ based films all had comparable shifts. Only the pure CX based showed a larger frequency shift (ca. $-130 \mathrm{~Hz}$ ), which correlated to the higher layer thickness.

According to the frequency shifts, the total amount of water $\Gamma_{\text {water }}$ was calculated and yielded $6.3 \pm 0.2 \mu \mathrm{g} / \mathrm{cm}^{2}$ for the $\mathrm{CC}$ based cellulose films (Table 1). The blend films systems exchanged $6.7 \pm 0.2(3: 1), 6.7 \pm 0.1(1: 1)$ and $6.7 \pm 0.2 \mu \mathrm{g}$ water $/ \mathrm{cm}^{2}(1: 3)$. With $7.4 \pm 0.1 \mu \mathrm{g} / \mathrm{cm}^{2}$ the total water uptake was higher in the CX based regenerated cellulose film. These values scaled with the mass of the cellulose films, therefore the film thickness needs to be taken into account for determining the degree of water uptake. The thickness was $50 \mathrm{~nm}$ for CC based layers, around $52 \mathrm{~nm}$ for the blend films and $57 \mathrm{~nm}$ for the CX based films. With the layer thickness and the density of cellulose $\left(1.5 \mathrm{~g} / \mathrm{cm}^{3}\right)$ (Holbery and Houston 2006), the dry mass of the cellulose films was determined. The dry mass was $7.5 \pm 0.2 \mu \mathrm{g} / \mathrm{cm}^{2}$ for the CC based cellulose films, $7.3 \pm 0.2$ (3:1), 
Table 1 Summary of the results from the QCM-D $\mathrm{H}_{2} \mathrm{O} / \mathrm{D}_{2} \mathrm{O}$ exchange experiment

\begin{tabular}{llll}
\hline & Dry mass $\left(\mu \mathrm{g} / \mathrm{cm}^{2}\right)$ & $\Gamma_{\text {water }}\left(\mu \mathrm{g} / \mathrm{cm}^{2}\right)$ & Water uptake $(\%)$ \\
\hline $\mathrm{CC}$ & $7.5 \pm 0.2$ & $6.3 \pm 0.2$ & $85 \pm 2$ \\
$3: 1$ & $7.3 \pm 0.2$ & $6.7 \pm 0.2$ & $92 \pm 1$ \\
$1: 1$ & $7.7 \pm 0.1$ & $6.7 \pm 0.1$ & $87 \pm 1$ \\
$1: 3$ & $7.9 \pm 0.1$ & $6.7 \pm 0.2$ & $84 \pm 1$ \\
$\mathrm{CX}$ & $8.7 \pm 0.1$ & $7.4 \pm 0.1$ & $85 \pm 1$ \\
\hline
\end{tabular}

$7.7 \pm 0.1(1: 1)$ and $7.9 \pm 0.1 \mu \mathrm{g} / \mathrm{cm}^{2}(1: 3)$ for the blend films and $8.7 \pm 0.2 \mu \mathrm{g} / \mathrm{cm}^{2}$ for the CX based films. The swelling behavior is presented in Fig. 7b and it can be concluded that there is no trend observable within the thin films derived from different cellulose sources. Only the $3: 1$ blend (CC:CX) featured a slightly higher water uptake $(92 \%)$, all the other films featured a water uptake capacity between 84 and $87 \%$.

\section{Conclusion}

Here, we introduced a new system for manufacturing cellulose thin films based on ecofriendly CC. Since CC is water soluble, the use of organic solvents is omitted compared to the other often employed cellulose derivative, TMSC. In addition, $\mathrm{CC}$ can be synthesized in large scale via environmentally friendly procedures. The regeneration process itself does not require any additional treatment but is induced by increasing the $\mathrm{NaOH}$ concentration during the spin-coating via evaporation of the water, as confirmed by IR and XPS spectroscopy. Such an in situ reaction in a polymer film during spin coating has no precedent in literature. Exposure to acid vapors or elevated temperature does not cause changes in the film morphology or chemistry of the films. Further, the film thickness can be easily adjusted within a range of 20 to $80 \mathrm{~nm}$ by varying the $\mathrm{CC}$ concentration. Only the increased surface roughness, caused by the high sodium hydroxide content in the solvent, could be a drawback for the processing of thin and well-defined cellulose layers based on $\mathrm{CC}$, depending on their purpose.

Blending of $\mathrm{CX}$ with $\mathrm{CC}$ is a promising method to partly substitute the frequently employed $\mathrm{CX}$ as source for regenerated cellulose products. Further, these all-cellulose blend films deliver an interesting possibility to investigate cellulose interfaces. Within this study, it could be shown that the blending and the regeneration of the cellulose derivatives do not lead to extensive phase separation regardless of the mixing ratio.

Acknowledgments Open access funding provided by Graz University of Technology. Lenzing AG and Fraunhofer Institute for Applied Polymer Research IAP are gratefully thanked for providing the cellulose xanthate stock solution and cellulose carbamate powder. Professor Gregor Trimmel and the PCCL are thanked for experimental support. EK is grateful for the support by the FinnCERES Materials Bioeconomy Ecosystem. We also thank the Dr. T. Mohan (University of Maribor) for experimental support in the QCM-D experiments.

Open Access This article is distributed under the terms of the Creative Commons Attribution 4.0 International License (http:// creativecommons.org/licenses/by/4.0/), which permits unrestricted use, distribution, and reproduction in any medium, provided you give appropriate credit to the original author(s) and the source, provide a link to the Creative Commons license, and indicate if changes were made.

\section{References}

Ehmann HMA, Werzer O, Pachmajer S, Mohan T, Amenitsch H, Resel R, Kornherr A, Stana-Kleinschek K, Kontturi E, Spirk S (2015) Surface-sensitive approach to interpreting supramolecular rearrangements in cellulose by synchrotron grazing incidence small-angle $\mathrm{x}$-ray scattering. ACS Macro Letters 4:713-716

Fink H-P, Ganster J, Lehmann A (2014) Progress in cellulose shaping: 20 years industrial case studies at Fraunhofer IAP. Cellulose 21:31-51

Fu F, Guo Y, Wang Y, Tan Q, Zhou J, Zhang L (2014) Structure and properties of the regenerated cellulose membranes prepared from cellulose carbamate in $\mathrm{NaOH} / \mathrm{ZnO}$ aqueous solution. Cellulose 21:2819-2830

Hämmerle FM (2011) The cellulose gap. Lenz Ber 89:12-21

Holbery J, Houston D (2006) Natural-fiber-reinforced polymer composites in automotive applications. JOM 58:80-86

Johansson L-S, Campbell JM (2004) Reproducible XPS on biopolymers: cellulose studies. Surf Interface Anal 36:1018-1022 
Keiji KK, Gordon JG (1985) The oscillation frequency of a quartz resonator in contact with liquid. Anal Chim Acta 175:99-105

Kittle JD, Du X, Jiang F, Qian C, Heinze T, Roman M, Esker AR (2011) Equilibrium water contents of cellulose films determined via solvent exchange and quartz crystal microbalance with dissipation monitoring. Biomacromol 12:2881-2887

Klemm D, Heublein B, Fink HP, Bohn A (2005) Cellulose: fascinating biopolymer and sustainable raw material. Angew Chem Int Ed 44:3358-3393

Kontturi E, Tammelin T, Österberg M (2006) Cellulose model films and the fundamental approach. Chem Soc Rev 35:1287-1304

Kunze J, Fink H-P (2005) Structural changes and activation of cellulose by caustic soda solution with urea. Macromolecular Symposia 223:175-188

Mohan T, Kargl R, Doliška A, Vesel A, Köstler S, Ribitsch V, Stana-Kleinschek K (2011) Wettability and surface composition of partly and fully regenerated cellulose thin films from trimethylsilyl cellulose. J Colloid Interface Sci 358:604-610

Mohan T, Spirk S, Kargl R, Doliška A, Vesel A, Salzmann I, Resel R, Ribitsch V, Stana-Kleinschek K (2012) Exploring the rearrangement of amorphous cellulose model thin films upon heat treatment. Soft Matter 8:9807-9815

Mohan T, Niegelhell K, Nagaraj C, Reishofer D, Spirk S, Olschewski A, Stana Kleinschek K, Kargl R (2017) Interaction of tissue engineering substrates with serum proteins and its influence on human primary endothelial cells. Biomacromol 18:413-421

Moidoveanu SC, David V (2002) Derivatization Reactions for Analytes with Various Functional Groups. J Chromatogr Libr 65:639-845

Nada A-A, Kamel S, El-Sakhawy M (2000) Thermal behaviour and infrared spectroscopy of cellulose carbamates. Polym Degrad Stab 70:347-355

Neufeld AK, Cole IS, Bond AM, Furman SA (2002) The initiation mechanism of corrosion of zinc by sodium chloride particle deposition. Corros Sci 44:555-572

Niegelhell K, Süßenbacher M, Jammernegg K, Ganner T, Schwendenwein D, Schwab H, Stelzer F, Plank H, Spirk S (2016) Enzymes as biodevelopers for nano- and micropatterned bicomponent biopolymer thin films. Biomacromol 17:3743-3749

Niinivaara E, Faustini M, Tammelin T, Kontturi E (2016) Mimicking the humidity response of the plant cell wall by using two-dimensional systems: the critical role of amorphous and crystalline polysaccharides. Langmuir 32:2032-2040
Owens DK, Wendt RC (1969) Estimation of the surface free energy of polymers. J Appl Polym Sci 13:1741-1747

Protz R, Weidel G, Lehmann A (2018) Man-made cellulosic fibers via the viscose process: new opportunities by cellulose carbamate. Lenz Ber 94:77-84

Rosenau T, Potthast A, Sixta H, Kosma P (2001) The chemistry of side reactions and byproduct formation in the system NMMO/cellulose (Lyocell process). Prog Polym Sci 26:1763-1837

Sauerbrey G (1959) Verwendung von Schwingquarzen zur Wägung dünner Schichten und zur Mikrowägung. Zeitschrift für Physik 155:206-222

Schaub M, Wenz G, Wegner G, Stein A, Klemm D (1993) Ultrathin films of cellulose on silicon wafers. Adv Mater 5:919-922

Shchukarev A, Sundberg B, Mellerowicz E, Persson P (2002) XPS study of living tree. Surf Interface Anal 34:284-288

Široký J, Blackburn RS, Bechtold T, Taylor J, White P (2010) Attenuated total reflectance Fourier-transform Infrared spectroscopy analysis of crystallinity changes in lyocell following continuous treatment with sodium hydroxide. Cellulose 17:103-115

Sixta H, Michud A, Hauru L, Asaadi S, Ma Y, King Alistair WT, Kilpeläinen I, Hummel M (2015) Ioncell-F: a high-strength regenerated cellulose fibre. Nord Pulp Pap Res J 30:43-57

Wang S, Lu A, Zhang L (2016) Recent advances in regenerated cellulose materials. Prog Polym Sci 53:169-206

Weißl M, Niegelhell K, Reishofer D, Zankel A, Innerlohinger J, Spirk S (2018) Homogeneous cellulose thin films by regeneration of cellulose xanthate: properties and characterization. Cellulose 25:711-721

Weißl M, Rath T, Sattelkow J, Plank H, Eyley S, Thielemans W, Trimmel G, Spirk S (2019) Multi-layered nanoscale cellulose/CuInS2 sandwich type thin films. Carbohydr Polym 203:219-227

Wendler F, Schulze T, Ciechanska D, Wesolowska E, Wawro D, Meister F, Budtova T, Liebner F (2012) Cellulose products from solutions: film, fibres and aerogels. The European polysaccharide network of excellence (EPNOE): research initiatives and results. Springer, Vienna

Xiong L-K, Yu G-M, Yin C-Y (2017) Synthesis and characterization of cellulose carbamate by liquid-solid phase method. Fibers Polym 18:88-94

Publisher's Note Springer Nature remains neutral with regard to jurisdictional claims in published maps and institutional affiliations. 